\title{
Broadcast:
}

\section{The historical development of}

\section{World Broadcasting and its impact reflected in}

\section{Brazil}

\author{
Gabriel Gomes de Oliveira \\ Yuzo Iano \\ Ana Carolina Borges \\ Reinaldo Padilha França \\ Pablo Minango \\ Diego Pajuelo
}

\section{CITE THIS ARTICLE}

de Oliveira, Gabriel Gomes, lano, Yuzo, Borges, Ana Carolina, França, Reinaldo Padilha, Minango, Pablo, Pajuelo, Diego; 2019. Broadcast: The historical development of World Broadcasting and its impact reflected in Brazil. SET INTERNATIONAL JOURNAL OF BROADCAST ENGINEERING. ISSN Print: 2446-9246 ISSN Online: 2446-9432. doi: 10.18580/setijbe.2019.11. Web Link: http://dx.doi.org/10.18580/setijbe.2019.11 


\title{
Broadcast: The historical development of World Broadcasting and its impact reflected in Brazil
}

\author{
Gabriel Gomes de Oliveira, Yuzo Iano, Ana Carolina Borges Monteiro, Reinaldo Padilha França, \\ Pablo Minango and. Diego Pajuelo
}

\begin{abstract}
Broadcasting is a method of message transfer to all receivers simultaneously, its services are those that perform the transmission of sounds and images (television) or just sounds (radios) to the general public. The present study was conducted by analyzing scientific papers present in the Scielo platform and main academic research platforms. These works were selected because they meet the criteria of time (2015-2019) and location (Brazil). The data below illustrates the main findings, creating a link between the first steps of world broadcasting and their respective impacts in Brazil.
\end{abstract}

Index Terms- Broadcast, Radio, Television, Media, Technology, Information.

\section{INTRODUCTION}

$\mathrm{T}$ he broadcast term, is the addition of "broad" meaning wide, or large-scale and "cast" is meant to send, design, and transmit. So, this growing wave towards the theme over the recent past, nowadays commonly associated with radio and television, is understood, however, its concept is much broader, since "broadcasting" is related to the transmission of sound and image of the radio. not get more radio waves thus reaching other types of electronic devices, broadcasting word has become archaic to mention the broadcast term. It is the process by which certain information is transmitted or transmitted to many receivers at the same time, where it is responsible for the transmission of any kind of media, through several ways (radio waves, satellite, cables, optical fibers, telephone lines), and on the internet, broadcasting is broadcasting videos and music, as it is usually [1] [2].

Moreover, with the spread of many different media, it is considered that broadcast is as an act of transmitting something, is a form of data transmission where all receivers

G. G. Oliveira is currently studying for a Master's degree at the State University of Campinas

Y. Iano is a teacher at the State University of Campinas

A. C. B. Monteiro is currently studying for a Ph.D.'s degree at the State University of Campinas

R. Padilha is currently studying for a Ph.D.'s degree at the State University of Campinas

D. Minango is currently studying for a Master's degree at the State University of Campinas

D. Pajuelo is currently studying for a Ph.D.'s degree at the State University of Campinas receive the same information simultaneously. Where currently the vast majority of the population has desires to share everything they like and want, with the rest of the world, therefore the services they are offering ways to make this feasible are becoming increasingly popular [3].

In addition, it is believed that not only residential users are responsible for the content explosion in the late 1990s and early 2000, but also globalization and digital transformations have brought with it the dissemination of the term broadcast [4][5].

As time went on, the internet has evolved, transforming the way people communicate, as they do today, with $4 \mathrm{G}$ technology circulating on mobile devices, and this progress is only just beginning. And along with the development of the $4 \mathrm{G}$ system, as well as the improvement behind Internet connection and content sharing services [6].

The very companies from various branches invest their millions in sound transmission solutions, image, and video over the internet and other means.

The development and expansion of digital technology produced an explosive increase in communication platforms in the last twenty years. Because of them, the diversity of opinions, existing ideas, and beliefs in society have greater opportunities to manifest itself in the public sphere. The foregoing, however, did not impede increasing regulatory intensity of the state, to ensure pluralism of information [7].

The last few years have been marked by a gradual and multiple increases of new portable media devices. Laptops, tablets, and mobile reproduce news, movies and shows anywhere, anytime. The traditional media such as radio and newspaper have been losing ground for different ways to communicate and share information, and the idea of a means to reach a unified mass no longer resonates within a technological configuration that presents [8].

The digital TV to replace the analog television broadcasts because it has the advantage of including interactive applications, such as research, programming and their schedules, emergency signs among others, as well as different types of high-definition signal quality (HD) and standard definition (SD) [7] [9].

With this briefly explained views, this paper aims to develop a review of the subject, on the various academic perspectives in tune with the subject in academia. 


\section{METHODOLOGY}

This study was conducted by analyzing scientific platform present in Scielo and main academic research platforms, being selected because they meet the criteria of time (20152019) and location (Brazil). The following data illustrate the main findings and trends related to the topic of the broadcast.

\section{HISTORICAL REVIEW}

Given the analysis of the selected articles note that the major peculiarities of the classical media Broadcasting, known as broadcasting have been classified by the radio stations.

Reginald Fessenden in 1900, pointing an alternator in which allowed the launch through the continuous wave, transmitting sound through waves. In 1906, Lee de Forest invented the triode, which in the future would be a device for the detection and amplification of radio signals, being at that time a vacuum tube containing three valves. This eventually served in the World War I, where it served as a mode of communication point to similar extent telephony and wireless networks, represented a significant slowdown in public broadcasting radio [3] [10].

Some academics believe that radio wave sound technology has its beginnings in the late nineteenth century, by the Italian Guglielmo Marconi, but should give merit to the creation of radio for Nikola Tesla, since Marconi used Tesla's patented technologies. The form of historically important as the radio model was performed approximately in 1920 in the United States [11 - 15].

Being in Europe, particularly in England, the first model evolved differently in the dimension in which, on September 1929, a landmark for world television, where British naturalized Scottish John Baird was allowed to air an experimental television service with the BBC of London. However, the US model was imposed to other countries, primarily from the radio, then television, while during 1960-1970, the use of the electromagnetic spectrum turned out to be available in most Western countries [13 - 19].

In the period of war, the transmission of electromagnetic waves was under the control of the governments of the countries in the conflict, which led to a delay in the deployment of broadcasting to the general public, being offset by the advances made in the period, which facilitate the growth of radio stations in the world postwar [12 - 15].

Under the supervision of the Navy, companies started to mass-produce and mass devices with standardized parts that were based on vacuum tube technology as a base. In the post-war, joining multiple alternators, created transmitters large transmission power on one hand, and receiving relatively inexpensive devices in their production, it became increasingly marked the difference between the complex technological devices [14 - 18].

Thus, the radio began to take its modern form when it came to sound signal amplification and emission technology technologically, since broadcasting has spread all over the world, and has become very complex and economically expensive, because of the use of vacuum tube, alternators, and when almost simultaneously developed one based on the receiving device technology (sets) simple and increasingly inexpensive. In possession of this technology, which could no longer be drained for military purposes, manufacturers have embarked on the creation of a mass-market to absorb the mass production of these simple devices and cheap [11 - 19].

Already alluded to the fact that the technological device's radio sending and receiving all have been patented. In addition to the technological and economic aspects, regulation indirectly exercised by the legal system of patents was another determining factor in the emergence of broadcasting, where these three aspects are retroactive all together [11 $19]$.

In the next period of the beginning of the war, companies founded Fessenden and Lee of Forest disappeared or had been bought. In particular, they have been its main aspurchased sets, patents. These purchases generated some of the great companies of the time. Lee from Forest to sell in 1913 its most valuable patent (the triode), resulting in AT\&T, the company that started then voice transmissions over long distances. In 1912, Edwin Armstrong understood the true triode's potential when he developed a feedback circuit that not only quite amplified the signal to allow the vacuum tube to generate radio waves [11 - 19].

The Navy led to the creation of the RCA (Radio Corporation of America) in 1919, which now holds the basic patents of GE (General Electric), AT \& T and American Marconi, where continued to face the radio science as an environment topic communication topic to be known commercially in line with this frame [11 - 19].

In turn, Westinghouse, left out of RCA, the company founded in 1920 that will eventually have been the first radio broadcast, the KDKA, where the broadcast was born as an environment for sale equipment [11 - 19].

The interests of the various RCA member companies were not convergent, since GE and Westinghouse were especially intellectual characteristic of the receivers and had been effectively specialized in the production and sale of such devices. This was a much more lucrative market than the market transmitters in which AT\&T had specialized [11 - 20].

Then the broadcasting Internet monopolist of the US telephone network sold its stake in RCA and created their stations broadcasting in 1922. Unlike other companies, the aim of AT \& T was not to sell receivers, but antecedently rent air time to potential bidders; however, this did not mean that the company should aim the broadcasting itself, as its business model was considered as a decal telephone usage time of sale for the transmission of voice, the peculiarity of AT\&T. In any case, the business model at the time aroused little interest, the result was a patent war, where AT\&T finally abandoned the broadcasting [14 - 21].

Patents are a way to indirectly regulate the use and economic exploitation of technological communication devices. The direct regulation operates especially for the right to emit. The need to regulate the use of the electromagnetic spectrum was historical originality with which the governments have faced in the first decades of the 20th century.

In the English case, the interests of various equipment manufacturers led to the creation of the British Broadcasting marketing year, after which, was transformed into a fully public company, the British Broadcasting Corporation (BBC) [15 - 22].

In the United States, the path was more complicated and are referred to herein only the essentials, the first law that regu- 
lated the use of the spectrum, the essential idea of the law was to enjoy access spectrum as a privilege, not a right automatically possessed by someone, the government granted four types of privileges: a bandwidth intended to be used by management; two other types of bandwidth intended for commercial use and, finally, a band consisting of only a single frequency intended to amateur operator's radio [16 23].

In order already mentioned, the battle involved spectrum integral control by the Navy through the adjustment need only to get turned after the explosion of the number of transmitters occurs during the years 20 [11 - 18].

A set of series of lectures organized by the United States Secretary of Commerce, through the years 1922-24, would perhaps decide the radio regulator in the authenticity, the conference would decide the general characteristics of the radio and television regulation that nowadays eventually change dominant in most Western countries [16 - 24].

Following the 1912 law, the basic idea remained that the electromagnetic spectrum is very restricted use of which is a privilege granted by the political authority in the form of licenses. The management would give two (first three) types spectrum usage licenses, the licenses A and B. The type B license allowed by emission power 500 watts and 1000 included in the frequency chez 750. The type of licenses emitted less than 500 watts (some are limited to 5 watts), and the frequencies were allocated between 1360 and 1500 chez. Gender licenses B favored stations rehearsing the sample broadcasting and could finance transmitters each more powerful and more expensive condition. On the contrary, amateurs, university, and religious associations are moved to a type of licenses, category A, with short distance and operating at frequencies subject to multiple interferences and tuning difficulties [12 - 20]

The solution turned regulation, consequently, for providing the broadcasting standard based on powerful, expensive transmitters and receivers humble and cheap, rather than the amateur copy of that in many cases were individuals who emitted either as received. Repeats that he was inseparable from growth thanks have just to companies like GE or Westinghouse, a market based on a simple receiving device becoming cheaper and intended to happen marketed in bulk

Then this new market required the creation of stations of broadcasting sending richly appealing content, in 1998, held in the evolution of radio [16 - 24].

The intersection between economic costs, technology, a market economy, and regulations led to conduct a communication standard in broadcasting, in which equal a complete asymmetry between two options: the 'emission' and 'reception'. Positions characterized the technological level by devices, in which a position receives signal and the other issues.

\section{BROADCAST IN BRAZIL}

The media are practical examples of broadcast distribution, and one or more transmission antennas refer to a television signal, or known as radio diffuser, through electromagnetic waves through TV or radio, that captures the signal [1 $16]$.

The radio in Brazil was first held in 1922, soon after, in 1923, the Henry Moirize masters and founded Roquette
Pinto held the first Brazilian broadcaster, known as the Radio Society of Rio de Janeiro. It is extremely important to point out that in 1893, in Brazil; Roberto Mandelli de Moura also sought similar effects in experiments, he made the first broad-casts in the world, Mediatrix and the Santa Teresa hill [1 - 16].

The broadcast was started in Brazil when Assis Chateaubriand, started a makeshift way, broadcasts of TV Tupi station in Sao Paulo, where the first transmission was with a musical performance, the famous taskmaster cinema of the time, Frei José Mojica [2 - 19].

The first content transmitted were adaptations of radio programs and plays, being everything done live because the only way to record sound and images at the time was in motion picture film. In 1980, he started internet in the Brazilian territory, with limited access to a scientific level, and academic, and in 1991 the Internet began to be used by local, state and federal agencies, finally after 15 years in 1995 internet obtained public access [13 - 19].

It took place in 1999 in Latin America, the first transmission of video/audio via the internet, where in the 2000s they were marked by the success of social networks. In 2002, one of the most popular social networks in Brazil, Orkut was created, two years later, in 2004, Mark Zuckerberg founded Facebook, which was to become the largest social network in the world [3 - 19].

The popularization of the broadcast concept came through the evolution of the Internet, with the beginning of YouTube, in 2005, and over the years, the internet has evolved, becoming increasingly popular and radically changing the way people to communicate. Giving a balance of 10 years, in 2015, the 4G (Fourth Generation mobile) arrives in Brazil, where this band is characterized by better signal penetration, allowing better coverage indoors [3 - 19].

With the release to the $4 \mathrm{G}$ network, the quality of streaming media content increases exponentially, where undoubtedly, the image quality is far superior to the analog signal. However, this is not the only or the main factor for change, all this reshuffling is going for the $700 \mathrm{MHz}$ bands currently used by analog TVs [2 - 19].

Currently, the mobile network uses a frequency of 2600 $\mathrm{MHz}$, having a length in the upper wave, thus facing greater difficulty in the period through various obstacles, usually walls. By owning a larger spread, the range of $700 \mathrm{MHz}$ has reached larger numbers of users, thus facilitating the purchase of equipment abroad, since hiding the compatibility issue, since these devices also use 4G frequency [11 - 24].

For the qualification of the internet service, and the development of $4 \mathrm{G}$, it takes to explore the scope of technology Live broadcast live streaming and it's already popularized by social networks today and the development of sharing and communication videos [11 - 24]

\section{TRENDS}

The new evolution, or technological revolution, has begun in telecommunications devices, impacting networks, and the companies providing these services, is in its initial stages, but is already overwhelming. The world of telecommunications is advancing over broadcasting services, it would no longer be legal regulation, pseudo-structure like a dam to contain and maintain separation. Since telecommunications 
networks demand differentiated content, the preparation of which is historically in the hands of broadcasting.

In addition to simply improving sound and reception quality, it is necessary to enable broadcasters to achieve equitable quality on the technology platform, so that they can differentiate themselves into their unique production, broadcasting, content and coverage area capabilities.

The convergence of TV with the internet, as technology advances, we now have TVs that offer internet access, with various apps available, and other features. People are abandoning pay-TV and have migrated to the Internet to watch videos, shows, shows, and movies, meaning that pay-TV service will have to change to maintain its customer base in the country.

For radio, again podcast appears with a growing trend. Like TV, radio and the newspaper, a podcast is an information medium, but the origin of podcast media is very recent and still in its infancy. growth process, especially in Brazil, where it reaches few people.

The podcast is like a radio show, but its primary difference and advantage is content on demand. You can be listened to whatever you want, anytime you want.

Images remain on the rise since the vertical video format is doubling year after year. Yet even more concern about privacy has increased considerably in the last three years. The lack of curated online content and the use of social networking algorithms has heightened polarization and extremist views.

The importance of sound broadcasting is acknowledged, it is natural that policies for scientific, technological and industrial development sustain a broadcast capable of meeting the challenges of the new millennium, since this is the future. It is essential to identify and understand the new requirements, adopting any technical solution without considering the ongoing transformations, resulting in the gradual improvement of Brazilian broadcasting.

\section{CONCLUSION}

Based on the broad applicability of this method is extremely important to develop studies that bring to light the history and evolution of techniques as comprehensive and notorious as the broadcasting. Thus, this paper aims to conduct a literature review on the history and the applicability of such technology this global trend. After all research, work should be well-founded based on methodology and strong literature.

Given the analysis of the analyzed papers realizes the broadcasting technique is an ancient methodology and that has accompanied man since the year 1920, undergoing changes and developments to monitor trends and needs over time. Where is clear the impact that the first steps from its patent dispute in the United States impacted the first content transmission made in Brazil reaching the current $4 \mathrm{G}$ scenarios.

Currently, note a strong link between the Internet and broadcasting as long as it is expected that with the advancement of $5 \mathrm{G}$ technologies allow greater synergy between both technologies employing higher speed and reliability in data transmission. Therefore, the broadcasting has shown great potential applicability not only in the areas of telecommunications, but currently in the transmission of data education, health, science, finance, and smart cities.

\section{REFERENCES}

[1] SALVADORI, MARIA ANGELA BORGES. LETTERS IN and rhythms: SCHOOL views, education and work Samba Brazilian (1930-1950).Educ. rev. [online]. 2018, vol.34.

[2] BECKER, Beatriz; MACHADO, Hector Leal; WALTZ, Igor and TASSINARI, Joana. The centrality of television news in the converging media environment: rethinking how the interactions between production and reception give directions to Rio 2016 Games Intercom, Rev. Bras. Ciênc.Common. [Online]. 2018, vol.41, n.3.

[3] MARTINS, Geraldo Vicente and. BULHOES, Ricardo Magalhães. Literature and religious spectacle on a short story of Marcelino Freire.Honor student. Lit. Bras. Contemp. [Online]. 2017 n.52.

[4] VILELA, IVAN. Hillbilly: culture, withstands INSTANCE and rooting. Honor student. av. [Online]. 2017, vol.31, n.9 0 .

ALMEIDA, Heloisa Buarque de. body education: the Women series and the promotion of medical and educational messages.Rev. Estud. Fem. [Online]. 2017, vol. $25, \mathrm{n} .1$.

[5] CARVALHO, Vanessa Brazil and of Massarani, Luísa Men and women scientists: gender issues in the two main television broadcasters Brasil.Intercom, Rev. Bras.Ciênc. Common. [Online]. 2017, vol.40, n.1 .

[6] Haussein Painis Fagundes. Brazilian communication journals record the research on the radio (2002-2012). Intercom, Rev. Bras. Ciênc. Common. [Online]. 2016, vol.39, n.3.

[7] CADIMA, Rui Francisco. European public TV to the "alienation" of Europa. Intercom Idea, Rev. Bras. Ciênc. Comun. [Online]. 2016, vol.39, n.2.

[8] DORNELAS, Rodrigo; GIANNINI, Susana Pimentel Pinto and FERREIRA, Leslie Piccolotto. World Voice Day news: analysis of reports on the Voice Campaign in Brazil. Codas [online]. 2015, vol.27, n.5.

[9] COSTA, Patrícia Coelho and. the PAULILO, André Luiz. HERALDS THE UNLIKELY, PIONEERS AND FILM radio EDUCATION IN BRAZIL (19201930).Educ. rev. [Online]. 2015, vol.31, n.2

[10]ANDRADE, Dilma Maria and to BARBOSA-WHITE, Anadergh. Synovitis and tenosynovitis in Brazil: an analysis of sickness benefits.Rev. bras. Epidemiol. [online]. 2015, vol.18, n.1.

[11] Mendonca, Veridiana Zocoler et al. The straw NUTRIENT RELEASE DE FORAGE intercropped with CORN WITH SOYBEANS AND SUCCESSION. Rev. Bras. Ciênc. Solo [online]. 2015, vol.39, n.1.

[12] NICHILE, Maria Cecilia F. De. The end of television, an end or a fresh start? Galaxy (Sao Paulo), Sao Paulo, n. 29, p. 290-292, June 2015.

[13] ONATE, Luis; GOMEZ, José and LAPO, Holger. ISDB-T ANALYSIS AND COMPARISON USING OFDM AND CC-OFDCM.Ingenius MODULATIONS [online]. 2019, no. 21, pp. 71-77. ISSN 1390-860X. http://dx.doi.org/10.17163/ings.n21.2019.07. 
[14] CHARNEY-BERDICHEWKY, John. Freedom of expression and informative pluralism: compatibilities and tensions in the context of television. Rev. Derecho Estado [online]. 2019, no.42, pp.117-148. ISSN 01229893. http://dx.doi.org/10.18601/01229893.n42.05.

[15] McElroy, Ruth, Christina Papagiannouli, and Hywel Wiliam. "Broadcasting after devolution: policy and critique in the Welsh media landscape 2008-2015." International Journal of Cultural Policy 25.3 (2019): 377 391.

[16] Ahn, C. H. "Status of Development of Broadcasting Technology for the Disabled." Electronics and Telecommunications Trends 34.3 (2019): 1-12.

[17] Frischmann, Brett. "The British Broadcasting Corporation case study." Routledge Handbook of the Study of the Commons (2019): 256.

[18] Arcos, Juan Manuel Velazquez, et al. "Optimum Efficiency on Broadcasting Communications." Telecommunication Systems. IntechOpen, 2019.

[19] Khosa, Risimati Maurice, and Miyelani Khosa. "Policy, regulation and implementation of advertiser-funded programming in South Africa: A case of the South African Broadcasting Corporation (SABC)." Journal of African Media Studies 11.1 (2019): 81-101.

[20] Irfan, Asmara, et al. "The Influence of Social Media on Public Value: A Systematic Review of Past Decade." Journal of Public Value and Administration Insights 2.1 (2019): 1-6.

[21] Pilar, Puertas-Molero, et al. "Impact of sports mass media on the behavior and health of society. A systematic review." International journal of environmental research and public health 16.3 (2019): 486.

[22] Suh, Young Ik, Taewook Chung, and Jong Min Kim. "The Relationship between Motivation of Social Viewing Experiences, Satisfaction, and Loyalty in Sports Broadcasting." International Journal of Computer Science in Sport 18.1 (2019): 148-159.

[23] Nande, Sushmita, Rucha Chitnis, and Simran Bose. "A Review Based Study of Gender Equality in Media." Available at SSRN 3396114 (2019).

[24] Priyam, A., et al. "Time Transfer based on the satellite digital TV broadcasting system." 2019 URSI AsiaPacific Radio Science Conference (AP-RASC). IEEE, 2019.

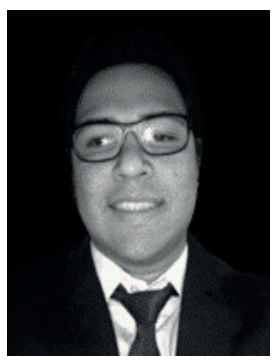

Gabriel Gomes de Oliveira. Graduated in Civil Engineering at UNIP University in 2018, studying for a Master's degree at Unicamp, FEEC (Faculty of Electrical and Computer Engineering), DECOM (Communications Department), Laboratory of Visual Communication (LCV) Currently researches and studies the Smart City area.

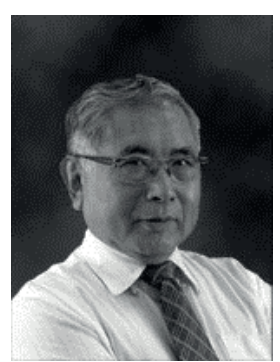

Yuzo Iano. B.Sc. (1972), M.Sc. (1974) and Ph.D. degrees (1986) in Electrical Eng. At Campinas, Brazil. Then he Has Been working in the technological production field, with one granted patent, patent applications filed 8 and 36 projects completed with research and development agencies. He has supervised 29 doctoral theses master's dissertations 49, 74 and 48 undergraduate initiation scientific works. He has participated in master's examination boards 100, doctoral 50 degrees, author of two books and more than 250 articles published. He is currently a teacher at Campinas, Editor-in-Chief of the SET International Journal of Broadcast Engineering and General Chair of the Brazilian Symposium on Technology (BTSym). $\mathrm{He}$ has experience in Electrical Engineering, with knowledge in Telecommunications, Electronics and Information Technology, Mainly in the field of audio-visual and multimedia communications.

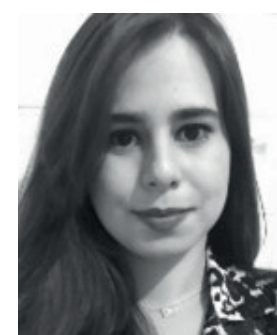

Ana Carolina Borges Monteiro. Graduated in Biomedicine from University Center Amparense - UNIFIA (2015). Currently is a Ph.D. Candidate by Department of Communications (DECOM), Faculty of Electrical and Computer Engineering (FEEC) at State University of Campinas (Unicamp) and a researcher at the Laboratory of Visual Communications (LCV). Also, she is currently the Registration Chair of the Brazilian Symposium on Technology (BTSym). Has expertise in the areas of Clinical Analysis and digital image processing through MATLAB software. This knowledge was acquired through the realization of research projects and internship in a municipal hospital, the experience Also in the revision of scientific works by acting as a reviewer in congresses

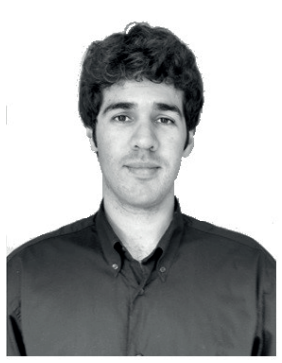

Reinaldo Padilha France. Graduated in Computer Engineering (University Regional Center of the Holy Spirit of Pinhal - 2014). Currently is a Ph.D. Candidate by Department of Communications (DECOM), Faculty of Electrical and Computer Engineering (FEEC) at State University of Campinas (Unicamp) and a researcher at the Laboratory of Visual Communications (LCV). Also, $\mathrm{He}$ is currently Chair Proceedings of the Brazilian Symposium on Technology (BTSym). Has interest and affinity in the area of technological and scientific research as well as knowledge in programming and development in $\mathrm{C} / \mathrm{C}++$, Java and .NET languages. The main topics of interest are Simulation, Operating Systems, Software Engineering, Wireless and Network, Internet of Things, Broadcasting and Telecommunications Systems. 


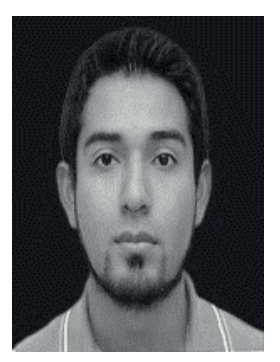

Pablo Mango. Graduated in Electronic Engineering at the Polytechnic University Salesian (UPS), Quito, Ecuador in 2017. Currently, He is a M.Sc. candidate by Department of Communications, Faculty of Electrical and Computer Engineering at State University of Campinas - Unicamp. Have research Interests in Deep Learning, Machine Learning, Digital Image Processing with Medical's images.

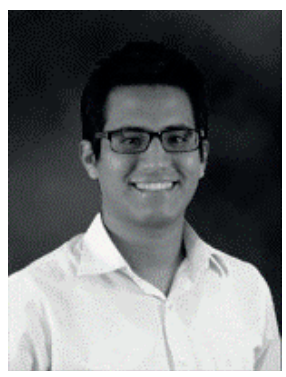

Diego Pajuelo, in Graduate Electrical Engineering from the Peruvian University of Applied Sciences (UPC), Lima, Peru in 2012. He is currently working towards his doctoral degree in Sciences and Telecommunications at Unicamp. His research interests are HDR Video and audio coding, Image processing, digital television and Satellite communications 